\title{
Student practices developing needs statements for design problems
}

\section{Mr. Robert P. Loweth, University of Michigan}

Robert P. Loweth is a Ph.D. candidate in the Department of Mechanical Engineering at the University of Michigan. He earned a B.S. in Engineering Sciences from Yale University, with a double major in East Asian Studies. He also holds a Graduate Certificate in Chinese and American Studies, jointly awarded by Johns Hopkins University and Nanjing University in China. His research focuses on how undergraduate engineering students solicit information from stakeholders and use this information to assess stakeholder needs as part of their curricular and co-curricular design projects. He is also a Graduate Facilitator for the Center for Socially Engaged Design.

\section{Dr. Shanna R. Daly, University of Michigan}

Shanna Daly is an Assistant Professor in Mechanical Engineering at the University of Michigan. She has a B.E. in Chemical Engineering from the University of Dayton (2003) and a Ph.D. in Engineering Education from Purdue University (2008). Her research focuses on strategies for design innovations through divergent and convergent thinking as well as through deep needs and community assessments using design ethnography, and translating those strategies to design tools and education. She teaches design and entrepreneurship courses at the undergraduate and graduate levels, focusing on front-end design processes.

\section{Jiangqiong Liu \\ Prof. Kathleen H. Sienko, University of Michigan}

Kathleen H. Sienko is an Arthur F. Thurnau Professor and Associate Professor of Mechanical Engineering at the University of Michigan (UM). She earned her Ph.D. in 2007 in Medical Engineering and Bioastronautics from the Harvard-MIT Division of Health Science and Technology, and holds an S.M. in Aeronautics \& Astronautics from MIT and a B.S. in Materials Engineering from the University of Kentucky. She co-founded the UM Center for Socially Engaged Design and directs both the UM Global Health Design Initiative (GHDI) and the Sienko Research Group. The Sienko Research Group is a multidisciplinary laboratory developing novel methodologies to create technological solutions that address pressing societal needs at the intersection of health care and engineering. Dr. Sienko is the recipient of an NSF CAREER award and several teaching awards including the ASME Engineering Education Donald N. Zwiep Innovation in Education Award, UM Teaching Innovation Prize, UM Undergraduate Teaching Award, and UM Distinguished Professor Award. 


\title{
Student Practices Developing Needs Statements for Design Problems
}

\begin{abstract}
Needs statements are concise articulations of design problems that indicate what changes are necessary for the problem to be resolved. Engineering students are increasingly participating in design projects during which they are developing needs statements based on stakeholder and contextual data; however, few studies have investigated student conceptions about developing needs statements. For this study, we followed an undergraduate student team as they completed training on developing needs statements and then developed initial needs statements for future design projects. While participants consistently described how needs statements should Balance breadth and specificity and Avoid embedding solutions, participants struggled to apply these conceptions in practice. Participants also did not discuss incorporating measurable outcome criteria into needs statements, even though this recommended practice was emphasized in the team's training. Based on these findings, we recommend that design instructors supplement needs statement pedagogy with concrete examples of effective and ineffective needs statements and use visual tools to illustrate different levels of needs statement breadth and specificity.
\end{abstract}

\section{Introduction}

The identification and subsequent definition of design problems is an important part of design processes [1]-[3]. The way that a design problem is defined establishes the project direction and delimits a range of acceptable solutions [4]-[6]. A key aspect of problem identification and definition is the development of "needs statements" (also known as "How Might We" statements [7], [8]) that concisely articulate the design problem and indicate what changes in outcome or conditions are necessary for the problem to be resolved [5], [9]. Needs statement development may be informed by several different types of information, including data gathered from stakeholders, contextual research, and academic literature [2]-[4], [9].

Gathering information from stakeholders to explore and define previously identified design problems is a core component of many undergraduate capstone design experiences [10], [11]. However, undergraduate engineering students are increasingly participating in co-curricular design projects that additionally involve the identification of design problems experienced by partner communities [12], [13]. While the development of needs statements represents one key way that engineering students can communicate and compare the design problems that they have identified [9], [12], few studies have explored how engineering students may approach needs statement development in practice as part of their projects. The goal of this study was to investigate undergraduate engineering students' conceptions about needs statement development, how their conceptions were impacted by training and practice related to developing needs statements, and challenges encountered by students while developing needs statements.

\section{Background}

\subsection{Recommended practices for developing needs statement}

Design textbooks [3], [9] and design guides [7], [8], [14] provide several recommendations for needs statement development. One common recommendation is that needs statements should specify what change should occur but not how that change should happen (i.e., the needs statement should be "solution neutral") [3], [8], [9]. For example, the needs statement "A way to 
reduce instances of waterborne illness in the community" emphasizes a specific desired change without committing the designer to any single solution in advance. As such, this statement provides space for the designer to explore a variety of solutions during ideation. By comparison, the needs statement "A need for new water filtration equipment in the community" pre-commits the designer to a specific solution while also failing to convey the underlying stakeholder need that may be motivating this solution choice. The latter statement might thus lead the designer to develop a solution that does not solve an actual problem [9], [14].

Another common recommendation is that needs statements should balance breadth and specificity to ensure that resulting solutions are as broadly impactful as possible while still addressing the intended primary needs [3], [7]-[9]. A needs statement that is too specific might over-constrain the design problem and lead the designer to develop a solution with limited impact [8], [9]. For example, a designer working with the needs statement "A way to reduce instances of waterborne illnesses from E. coli infections" might fail to develop a solution that also addresses other types of waterborne illnesses that may be more relevant to stakeholders. By comparison, a needs statement that is too broad risks overgeneralizing the problem and may fail to emphasize the most pressing needs experienced by stakeholders [8], [9], [14]. For example, the statement "A way to clean water in the community" may be too vague about the necessary change that needs to occur: a designer might develop an effective means to remove sediment when the true problem is waterborne bacteria. The right balance of breadth and specificity is context-dependent; design textbooks and guides thus recommend that designers explore multiple problem framings to identify the optimal balance for their project [8], [9], [14].

A third recommendation is that needs statements should include measurable outcome criteria that designers can use to evaluate whether the design problem has been addressed by a solution [9]. For example, in the case of the needs statement "A way to reduce instances of waterborne illness in the community," it is possible to measure the degree to which instances of waterborne illnesses have been reduced. By comparison, the statement "A way to fight waterborne illness in the community" does not specify measurable criteria; it is unclear how to evaluate the degree to which waterborne illnesses have been "fought." Designers working with the latter statement might struggle to determine how well potential solutions address the identified need.

2.2 Needs statements in the context of student problem identification and definition processes Previous studies have described several challenges that engineering students may encounter while identifying and defining design problems that could impact needs statement development. For example, Wood and Mattson [15] in a meta-analysis of Engineers Without Borders (EWB) projects found that many student teams made inaccurate assumptions about stakeholder needs when identifying and defining design problems. Common factors that may lead students to make these inaccurate assumptions include cultural differences between the students and stakeholders [13], [15], lack of student-stakeholder interactions [15]-[17], and student difficulties soliciting relevant information from stakeholders [10], [15], [18]. Inaccurate assumptions about needs could cause students to develop needs statements that do not align with true stakeholder needs.

Furthermore, other studies have shown that engineering students may struggle to collect and analyze qualitative stakeholder data as part of their problem identification and definition processes [10], [13], [19]. These data collection and analysis challenges are partially related to 
student difficulties encountered while planning information gathering interactions with stakeholders [10], [13], finding and accessing stakeholders who can best provide needed information [10], [13], and translating conflicting or ambiguous stakeholder responses into specific needs and/or requirements [10], [18], [19]. Problem identification and definition processes also generate large amounts of qualitative data that engineering students, who rarely receive formal training related to qualitative analysis as part of standard engineering curricula, may struggle to process effectively [12], [13], [19]. Challenges encountered while collecting and analyzing qualitative data could thus lead students to use fewer and less varied sources of information when identifying and defining their design problems [10], [13], [19].

However, an initial literature review did not reveal prior studies that had directly investigated student conceptions or processes related to developing needs statements based on stakeholder data. As such, we do not know what challenges students may encounter when synthesizing qualitative data that are unique to needs statement development. We also do not know what conceptions students may have about developing needs statements or how these conceptions compare to recommended practices. The goal of this study was to address these knowledge gaps to inform future design pedagogy around needs statement development.

\section{Methods}

\subsection{Research questions}

This study sought to investigate undergraduate engineering students' conceptions about developing needs statements and how their conceptions were impacted by training and practice related to needs statement development. We also wanted to explore the challenges that engineering students encountered while developing needs statements based on stakeholder data. Our study was thus guided by the following research questions:

1. What do engineering students think are recommended practices for translating stakeholder data into needs statements? How do these conceptions change as a result of relevant training and practice?

2. What challenges do engineering students encounter when translating their data into needs statements?

\section{$\underline{3.2 \text { Design context }}$}

Data for this study were collected from a team of twelve students who conducted a needs assessment in a rural South American partner community. Qualitative research often focuses on deep exploration of specific cases to identify elements of experiences that may be transferrable to other design contexts [20]-[22], and previous longitudinal qualitative studies of student design processes have similarly focused on the experiences of individual teams [13], [23]. The needs assessment team that participated in our study was part of a co-curricular organization specializing in medical device design for low-resource settings. During their needs assessment, the team spent seven weeks (hereafter referred to as the "pre-assessment phase") at their home university preparing to gather data in their partner community and one week (hereafter referred to as the "assessment phase") in the partner community conducting interviews and observations with local stakeholders [13]. Participants then used these interview and observational data to develop initial needs statements for future design projects. This study was approved by the university's Institutional Review Board. 
During their pre-assessment phase, the team completed training modules related to conducting observations, conducting a needs assessment, and developing needs statements through the University of Michigan's Center for Socially Engaged Design (C-SED) [24]. These modules were completed individually and included review of recommended practices as well as in-person practice and coaching [25]. Each module took about five hours to complete. The team's needs statements training drew heavily from recommended practices described in Zenios et al. [9] and the Stanford d.school design thinking bootleg (previously known as the bootcamp bootleg) [7].

\subsection{Participants}

Demographic information for the 12 members of the needs assessment team are shown in Table 1 (names are pseudonyms). Participants generally had one to three semesters of curricular design experience and/or 6 to 18 months of co-curricular/internship design experience, depending upon their year and program. Although several participants had previously worked on design projects with clearly defined needs statements, only Emma had experience developing needs statements.

Table 1. Participant demographics

\begin{tabular}{|c|c|c|c|c|c|}
\hline Pseudonym & Year & Sex & $\begin{array}{l}\text { Race/ } \\
\text { Ethnicity }\end{array}$ & Primary Major & $\begin{array}{l}\text { Secondary } \\
\text { Major/Minor }\end{array}$ \\
\hline John & Freshman & M & White & Public Health & \\
\hline Emma (Lead) & Master's & $\mathrm{F}$ & White & Biomedical Engineering & \\
\hline Isabelle & Sophomore & $\mathrm{F}$ & Asian & Chemical Engineering & \\
\hline Sophie & Freshman & $\mathrm{F}$ & Asian & Biomedical Engineering & \\
\hline Jill & Sophomore & $\mathrm{F}$ & White & Industrial Engineering & $\begin{array}{l}\text { International Minor } \\
\text { for Engineering }\end{array}$ \\
\hline Stephanie & Junior & $\mathrm{F}$ & $\begin{array}{l}\text { Asian \& } \\
\text { White }\end{array}$ & Biomedical Engineering & American Culture \\
\hline Chloe & Freshman & $\mathrm{F}$ & White & Biomedical Engineering & \\
\hline Maria & Freshman & $\mathrm{F}$ & Hispanic & Public Health & Spanish \\
\hline Emily & Sophomore & $\mathrm{F}$ & $\begin{array}{l}\text { Asian \& } \\
\text { White }\end{array}$ & Mechanical Engineering & Music \\
\hline Melissa & Freshman & $\mathrm{F}$ & Asian & Biomedical Engineering & Creative Writing \\
\hline Arya & Freshman & $\mathrm{F}$ & Asian & Electrical Engineering & Business \\
\hline Alli (Lead) & Junior & $\mathrm{F}$ & White & Mechanical Engineering & $\begin{array}{l}\text { Multidisciplinary } \\
\text { Design }\end{array}$ \\
\hline
\end{tabular}

\section{$\underline{\text { 3.4 Data collection }}$}

We sought to collect deep detail about participants' conceptions relating to needs statement development to facilitate the identification of elements from these conceptions that might be transferrable to other engineering students [20]-[22]. As such, we interviewed each participant three times over the course of the study: at the beginning of the team's pre-assessment phase, at the end of the team's pre-assessment phase, and at the end of the team's assessment phase (see Figure 1). We conducted beginning and end of pre-assessment phase interviews in four groups of three team members (same groups for both) so that participants could elaborate on each other's responses. We conducted end of assessment phase interviews individually to allow more opportunities to explore individual conceptions and experiences. 


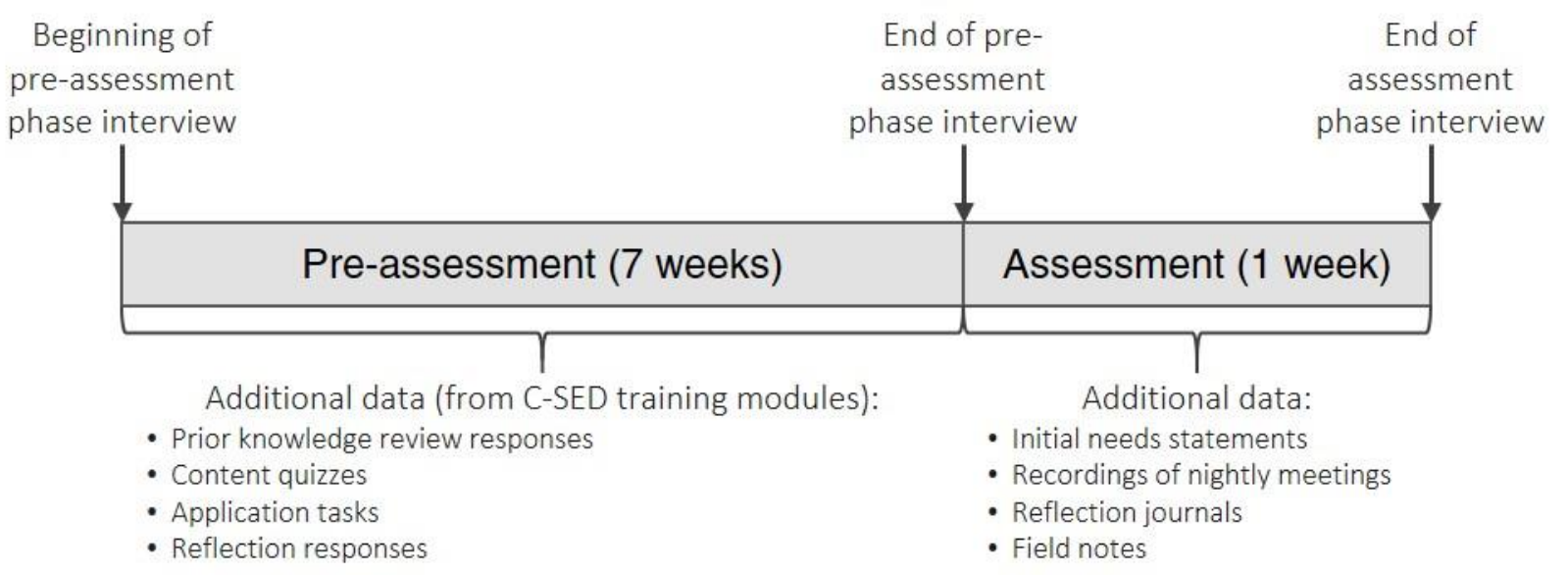

Figure 1. Data collection timeline

We developed protocols for each interview following recommended practices for protocol development [20], [26], [27]. Sample questions are shown in Table 2. While these questions served as a starting point, the semi-structured interview format helped us explore interesting responses and gather deep detail about participant conceptions. Interview recordings (11 hours of audio) were transcribed to facilitate data analysis. We also collected additional data generated during the team's pre-assessment and assessment activities. Additional pre-assessment phase data included C-SED training module deliverables such as prior knowledge reviews, content quizzes, application tasks, and reflections. Additional assessment phase data included a list of initial needs statements, recordings of nightly meetings, individual reflection journals, and individual field notes. These additional data were used to help verify that participant interview responses accurately reflected participant conceptions about developing needs statements.

Table 2. Examples of protocol questions pertaining to needs statement development

\begin{tabular}{|c|c|}
\hline & Questions \\
\hline $\begin{array}{l}\text { Beginning of } \\
\text { pre-assessment } \\
\text { phase interview }\end{array}$ & $\begin{array}{l}\text { 1. What prior experiences do you have with creating needs statements? } \\
\text { 2. What would you say are the qualities of a good needs statement? } \\
\text { 3. How about the qualities of bad needs statements? }\end{array}$ \\
\hline $\begin{array}{l}\text { End of pre- } \\
\text { assessment } \\
\text { phase interview }\end{array}$ & $\begin{array}{l}\text { 1. Based upon your preparation, how do you think you might approach } \\
\text { crafting needs statements after collecting stakeholder data? } \\
\text { 2. What do you think are the qualities of a good needs statement? } \\
\text { 3. What challenges do you anticipate encountering when crafting needs } \\
\text { statements? }\end{array}$ \\
\hline $\begin{array}{l}\text { End of } \\
\text { assessment } \\
\text { phase interview }\end{array}$ & $\begin{array}{l}\text { 1. Could you tell me about the needs statements that you have produced? } \\
\text { 2. Could you describe the process of crafting a needs statement? } \\
\text { 3. What would you say are aspects of your needs statement that make it a } \\
\text { good needs statement? } \\
\text { 4. Do you think there is anything about your needs statement that might } \\
\text { be improved? }\end{array}$ \\
\hline
\end{tabular}




\subsection{Data analysis}

Our analysis focused on identifying and describing participant conceptions of recommended practices for developing needs statements, as well as key challenges that participants encountered. First, two members of the research team reviewed the transcripts of participant interviews several times to familiarize themselves with the data. They then, following an inductive coding approach, identified distinct participant responses to the questions in Table 2; similar responses were grouped together to form key themes that represented participant conceptions of recommended practices for developing needs statement and challenges that participants encountered while developing needs statements [27]-[29]. After identifying this initial list of themes, the two researchers discussed their respective interpretations of these themes and settled on shared definitions for each theme. They then reviewed the transcripts again to identify any remaining responses that had been missed during the first round of coding and that aligned with one of the identified themes. This process of iterative review and consensus building, as well as comparison of interview responses to additional data submitted by participants, helped us establish the validity and reliability of the identified themes [20]-[22]. By the end of our analysis process, the two researchers reached full negotiated agreement on the definitions and prevalence of identified themes in our data set [30].

\section{Findings}

Findings are presented according to the timeline shown in Figure 2. Section 4.1 describes key conceptions of recommended practices for developing needs statements expressed by participants, as well as the evolution of these conceptions over time. Section 4.2 describes key challenges experienced by participants during needs statement development.

Key conceptions of recommended practices for developing needs statements

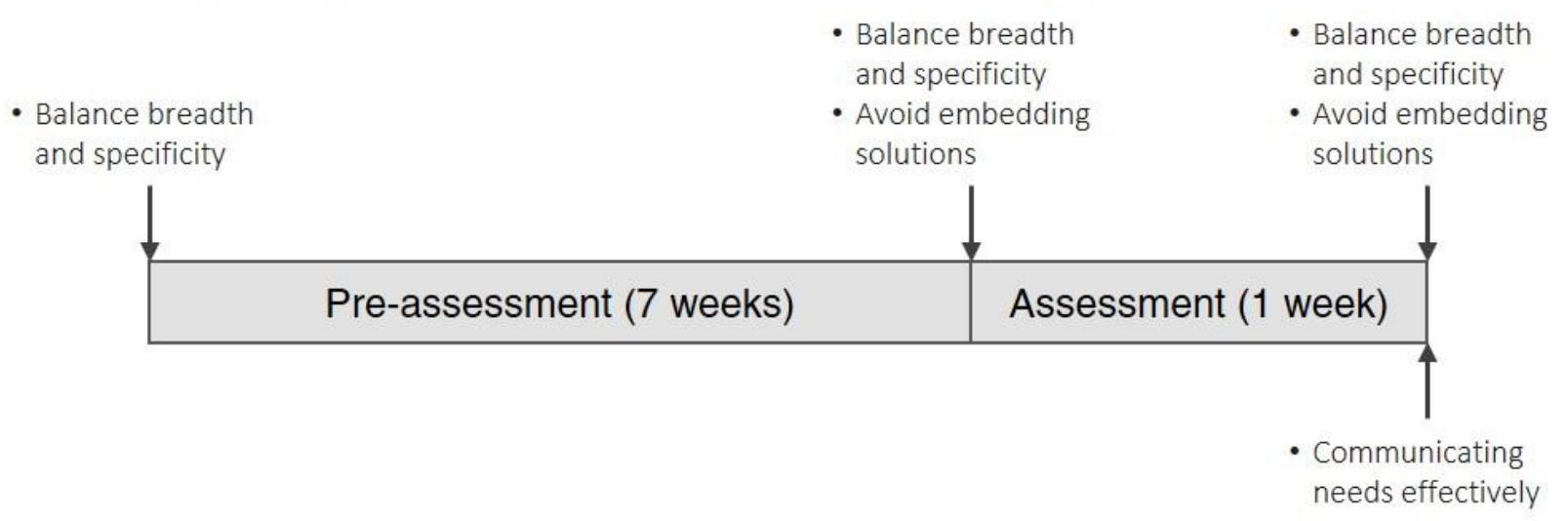

Key challenges encountered

Figure 2. Key conceptions of recommended practices for developing needs statements and challenges encountered by participants over time

4.1 Key participant conceptions of recommended practices for developing needs statements During the beginning of pre-assessment phase group interviews, all four groups discussed how needs statements should Balance breadth and specificity, i.e., accurately describe the design problem without narrowing the range of potential solutions. As one group explained: 
Have [the needs statement] be concise and clear... I think it shouldn't obviously lead one to think of a design. [The needs statement] should keep it open-ended for multiple designs and solutions. (Melissa \& Arya)

In other words, participants began the study with basic conceptions that need statements should clearly communicate the design problem without limiting the range of solutions. However, discussions of this conception tended to be vague since participants had limited prior experience developing needs statements.

All four groups continued to emphasize Balance breadth and specificity as an important practice during the end of pre-assessment phase group interviews, which occurred after the team completed their training on developing needs statements. At this point, participants began to elaborate on the factors that might determine breadth and specificity in needs statements. As John described while discussing the team's training:

Walking that fine line of not being too specific or too broad was kind of difficult for me. It helps if I keep it in context 'cause I know for one of my needs I could have made it more broad, but in the context of the situation it made sense to keep it as specific as it was. The needs statement is very difficult 'cause you have to hand choose every single word. (John)

Here, John pointed out that design context can help designers evaluate the right balance of breadth and specificity when developing needs statements. However, incorporating that balance into needs statements can be difficult. Designers should carefully consider how to word their statements to communicate the right balance of breadth and specificity.

During the end of pre-assessment phase group interviews, all four groups also discussed for the first time the need to Avoid embedding solutions in needs statements, such as by specifying a need for a specific object. For instance, Jill described how

We'll have to focus on who the need is for and why the need is present because that'll help us not focus on the solution and not be implanting a solution into our statement. (Jill)

In other words, Jill highlighted how the team should focus on aspects of the need, such as who was experiencing the need and why, rather than solutions when developing needs statements.

Finally, participant discussions during the end of assessment phase individual interviews also centered around Balancing breadth and specificity and Avoiding embedding solutions, with nine out of twelve participants citing the former and eight out of twelve participants citing the latter. In addition, descriptions of these two practices frequently converged. For example:

I think the balance between being general and specific, because it's very easy to say, "We need to do this," and have a solution there, ... but not putting solutions in makes [the needs statement] so much better, even though it may seem more helpful if you have it more specific, it's actually so much better if you don't... It gives you more opportunities for solutions and stuff and a broader place to start, because then if the one solution that you were thinking of doesn't work out, you have so many other options if you're looking at it that way. (Emily) 
Here, Emily started by describing how designers should Balance breadth and specificity when developing needs statements. Emily then discussed embedding a solution as an example of a needs statement being too specific because the embedded solution removes opportunities for exploring other options. This quote thus shows how participants developed specific and closely related conceptions of Balancing breadth and specificity and Avoiding embedding solutions through their needs assessment experiences.

4.2 Key challenges encountered by participants when developing needs statements Although participants were able to describe two specific conceptions related to developing effective needs statements, they struggled to apply these conceptions in practice. For instance, eleven out of twelve participants in the end of assessment phase individual interviews indicated that, given their limited experience with developing needs statements, they struggled to identify what an ideal needs statement should look and/or feel like. As Alli pointed out:

We all wrote our [needs statements] a little bit differently, and each person had their own personal structure that they liked. I don't know if there's one that's technically correct, or if they all work? I guess I just don't even know what a needs statement is supposed to feel like when you read it. That was something that I was unsure of. (Alli)

Alli highlighted a fundamental knowledge gap experienced by participants: beyond applying recommended practices, how could participants verify that they had effectively communicated the needs that they had identified? Seven out of twelve participants further elaborated that uncertainty about how to communicate needs effectively also hindered their ability to develop needs statements according to their conceptions of recommended practices. For example:

I don't think any of the [needs statements] I wrote are correctly formatted. I tried not to embed a solution... They just ended up being very broad. (Isabelle)

In other words, Isabelle felt that her struggles with communicating needs also made it more difficult for her to Balance breadth and specificity properly while developing needs statements.

In addition to participant descriptions of challenges encountered while developing needs statements, we also collected a list of initial needs statements from the team. These needs statements were developed individually by participants before being compiled into a full team list to compare and evaluate. The following list presents the initial needs statements developed by participants related to water quality:

1. A need for easy access to a safe source of water.

2. A way to access clean/treated/potable water to decrease health consequences like severe diarrhea.

3. Need convenient way to treat water and educate population about the benefits of treated water.

4. A way to supply or collect clean water for drinking and cooking.

5. A need for access to clean drinking water.

6. A need for easily accessible water.

7. A need for easy access to clean water. 
8. A need to decrease the incidence of water-borne illness.

9. A way to access drinking water that is safe to drink, shower, and cook with because it can reduce dehydration and illness.

10. A need for clean, accessible, and affordable drinking water.

As discussed by participants, this list of needs statements represents a variety of different formats (e.g., starting the needs statement with "A need for..." vs "A way to...") and levels of detail. Without additional information about the community context, needs statements 1,6 , and 7 seem too broad to accurately communicate the design problem, while needs statement 9 may be too specific in describing the preferred impact of the solution. In addition, statements that specifically referenced access to clean drinking water, such as needs statements $1,2,4,5,7,9$, and 10, may not fully and clearly communicate the fundamental needs of the community (i.e., is the fundamental need more related to water access or water cleanliness?). As such, this list of initial needs statements seems to reflect the challenges with developing needs statements that participants described during their interviews. The team ultimately chose needs statement 8 as their preferred needs statement related to water quality because they felt that it best reflected their conceptions of Balancing breadth and specificity and Avoiding embedding solutions.

\section{Discussion}

In summary, participants described two key conceptions of recommended practices for needs statement development: Balance breadth and specificity and Avoid embedding solutions. Participants had initial ideas about Balancing breadth and specificity that became more specific following training and practice developing needs statements. Participants also learned to Avoid embedding solutions (i.e., specify what change should occur but not how that change should happen) as a result of their training. Both of these conceptions were consistent with recommended practices for needs statement development [3], [7]-[9].

While design textbooks and design guides often describe specifying the what not the how and balancing breadth and specificity as separate recommended practices for developing needs statements [3], [7]-[9], participant conceptions related to these two practices tended to converge during end of assessment phase individual interviews. In other words, participants frequently mentioned embedding solutions as a way to make needs statements too specific. Given the frequent conflation of these two practices by participants, it is unclear to what extent participants were aware of other ways to make needs statements too specific aside from embedding solutions.

Similar to previous accounts of engineering students struggling to synthesize qualitative data while developing stakeholder requirements [10], [19], we found that students encountered difficulties developing needs statements based on their stakeholder data. Although training and practice helped participants describe the importance of Balancing breadth and specificity and Avoiding embedding solutions when developing needs statements, participants were still unsure how best to apply these conceptions in practice to help them effectively communicate the needs they had identified. These findings are consistent with previous studies [31] and frameworks [32], [33] related to design skill development, all of which have emphasized that student knowledge may be context dependent and that being able to describe recommended practices does not necessarily mean that students will be able to apply these practices in their design work. Participants may also have struggled to avoid embedding potentially inaccurate assumptions 
about stakeholder needs in their needs statements [13], [15]; participants recognized that Avoiding embedding solutions was one way to avoid making assumptions about needs but were unsure how to make their needs statements specific enough without making other assumptions.

Furthermore, participants did not discuss how they might incorporate measurable outcome criteria into their needs statements [9], even though this recommended practice was emphasized in the training that the team completed. This omission may represent an additional knowledge gap; while several (but not all) needs statements developed by the team seem to incorporate measurable outcome criteria, it is unclear if participants incorporated these criteria intentionally. Unfortunately, our data do not allow us to explore why participants did not describe this recommended practice during their interviews.

One limitation of our study was that our last interview with participants occurred immediately after participants had developed their initial needs statements. As such, it is unclear how participant conceptions of recommended practices for needs statement development might have continued to evolve as the team continued to iterate on the needs statements they had developed and reflect on their process of developing need statements. Another limitation was that it is unclear which learning gains from the team's training and practice related to developing needs statements remained salient over time, given that participants may not have had consistent opportunities after this experience to keep practicing what they had learned [34].

The findings from this study have three main implications for future engineering design pedagogy. First, our findings suggest that engineering students need additional support for needs statement development that goes beyond instruction about recommended practices. A common request that we heard from our participants was a desire for more examples and frameworks that they could use as inspiration when developing needs statements. We have since used this feedback to inform iterations on our pedagogical content related to needs statement development. Anecdotally, we have found that providing multiple examples of both effective and ineffective needs statements for students to compare has helped students comprehend and apply recommended practices related to specifying the what not the how and describing measurable outcome criteria. However, more work needs to be done to validate these initial observations and to determine what other types of pedagogical support might be helpful.

In addition, engineering students also need tools that can help them apply recommended practices for needs statement development, especially balancing breadth and specificity. The challenge with teaching this recommended practice is that evaluations of specificity are contextdependent; a statement that is too specific in one design context could be too broad in a different context and the optimal balance between breadth and specificity may vary depending on the project. "Why-How Laddering" is one pre-existing tool that is meant to help designers identify the right level of breadth and specificity when describing needs [7]. Anecdotally, we have found that laddering needs statements according to the Why-How framework (see Appendix A for an example provided by C-SED) can help students identify the degree of specificity that best aligns with their project scope. However, more work needs to be done to validate "Why-How Laddering" as an effective tool for developing needs statements and to identify other types of tools that could also support student approaches to needs statement development. 
Finally, design instructors can use the descriptions of recommended practices in Section 2.1 to develop pedagogy related to needs statement development. Zenios et al. [9] provides the most indepth descriptions of these recommended practices that we have found thus far, albeit in the specific context of medical device design. Our study, as well as the examples of needs statements in IDEO's Field Guide to Human-Centered Design [8] and the Stanford d.school's design thinking bootleg [7], suggest that these recommended practices for needs statement development are likely transferable to other engineering design contexts as well.

\section{Conclusion}

This study explored engineering student conceptions related to needs statement development, how these conceptions changed following relevant training and practice, and challenges encountered by engineering students while developing needs statements. Participants emphasized two main practices for developing needs statements, Balance breadth and specificity and Avoid embedding solutions, both of which were consistent with recommended practices from design textbooks and guides. Although participant descriptions of these practices increased in specificity following training and practice, participants struggled to apply these practices effectively when developing needs statements from stakeholder data. Participants also did not describe conceptions related to incorporating measurable outcome criteria into needs statements even though this practice was covered in the team's training materials; this omission may represent an additional knowledge gap. Our findings suggest that students need additional pedagogical support and tools that can help them apply recommended practices when developing needs statements. The detailed descriptions of student conceptions and challenges described in this paper can help support the shaping of this pedagogy.

\section{Acknowledgements}

This material is based upon work supported by the National Science Foundation under Grant No. 1611687. Any opinions, findings, and conclusions or recommendations expressed in this material are those of the author(s) and do not necessarily reflect the views of the National Science Foundation. The research team would also like to express their gratitude to Charlie Michaels, Tallie Ritter, Jessica Kahn, Tanner Jones, and Christian Casanova at the University of Michigan's Center for Socially Engaged Design for sharing and allowing us to use the needs statement Why-How Laddering example shown in Appendix A.

\section{References}

[1] D. G. Ullman, The mechanical design process, 4th ed. Boston, MA: McGraw-Hill Higher Education, 2010.

[2] G. E. Dieter and L. C. Schmidt, Engineering Design, 5th ed. New York, NY: McGraw-Hill, 2013.

[3] K. T. Ulrich and S. D. Eppinger, Product Design and Development, 5th ed. New York, NY: McGraw-Hill, 2012.

[4] J. Restrepo and H. Christiaans, "Problem structuring and information access in design," $J$. Des. Res., vol. 4, no. 2, pp. 1551-1569, 2004, doi: 10.1504/JDR.2004.009842.

[5] E. Silk, S. Daly, K. Jablokow, S. Yilmaz, and M. Berg, "The design problem framework: Using adaption-innovation theory to construct design problem statements," in Proceedings of the 121st ASEE Annual Conference \& Exposition, Indianapolis, IN, Jun. 2014. 
[6] K. Dorst, Frame Innovation: Create New Thinking by Design. Cambridge, MA: MIT Press, 2015.

[7] S. Doorley, S. Holcomb, P. Klebahn, K. Segovia, and J. Utley, “design thinking bootleg." Hasso Plattner Institute of Design at Stanford, 2018, Accessed: Sep. 04, 2019. [Online]. Available: https://dschool.stanford.edu/s/9wuqfxx68fy8xu67khdiliueusae4i.

[8] IDEO, The Field Guide to Human-Centered Design. Canada: IDEO.org, 2015.

[9] S. Zenios, J. Makower, and P. Yock, Eds., Biodesign: The Process of Innovating Medical Technologies. Cambridge, UK: Cambridge University Press, 2010.

[10] I. Mohedas, S. R. Daly, and K. H. Sienko, "Design ethnography in capstone design: Investigating student use and perceptions," Int. J. Eng. Educ., vol. 30, no. 4, pp. 880-900, 2014.

[11] S. Howe and J. Goldberg, "Engineering Capstone Design Education: Current Practices, Emerging Trends, and Successful Strategies," in Design Education Today: Technical Contexts, Programs and Best Practices, D. Schaefer, G. Coates, and C. Eckert, Eds. Cham, Switzerland: Springer International, 2019, pp. 115-148.

[12] K. H. Sienko et al., "Global health design: Clinical immersion, opportunity identification and definition, and design experiences," Int. J. Eng. Educ., vol. 34, no. 2(B), pp. 780-800, 2018.

[13] R. P. Loweth, S. R. Daly, J. Liu, and K. H. Sienko, "Assessing needs in a cross-cultural design project: Student perspectives and challenges," Int. J. Eng. Educ., vol. 36, no. 2, pp. 712-731, 2020.

[14] A. Smith and B. Linder, "IDDS Design Workbook." International Development Innovation Network, Oct. 26, 2014, [Online]. Available: http://www.idin.org/resources/curriculum/idds-design-notebook.

[15] A. E. Wood and C. A. Mattson, "Design for the developing world: Common pitfalls and how to avoid them," J. Mech. Des., vol. 138, no. 3, p. 031101, Jan. 2016, doi: 10.1115/1.4032195.

[16] H. van Rijn, F. Sleeswijk Visser, P. J. Stappers, and A. D. Özakar, "Achieving empathy with users: The effects of different sources of information," CoDesign, vol. 7, no. 2, pp. 6577, Jun. 2011, doi: 10.1080/15710882.2011.609889.

[17] R. P. Loweth, S. R. Daly, K. H. Sienko, A. Hortop, and E. A. Strehl, "Student designers' interactions with users in capstone design projects: A comparison across teams," in Proceedings of the ASEE 126th Annual Conference \& Exposition, Tampa, FL, Jun. 2019.

[18] D. K. Ho, J. Ma, and Y. Lee, "Empathy@ design research: A phenomenological study on young people experiencing participatory design for social inclusion," CoDesign, vol. 7, no. 2, pp. 95-106, Jun. 2011, doi: 10.1080/15710882.2011.609893.

[19] I. Mohedas, S. R. Daly, and K. H. Sienko, "Gathering and synthesizing information during the development of user requirements and engineering specifications," in Proceedings of the 121st ASEE Annual Conference and Exposition, Indianapolis, IN, Jun. 2014.

[20] J. A. Leydens, B. M. Moskal, and M. J. Pavelich, "Qualitative methods used in the assessment of engineering education,” J. Eng. Educ., vol. 93, no. 1, pp. 65-72, Jan. 2004, doi: 10.1002/j.2168-9830.2004.tb00789.x.

[21] M. Borrego, E. P. Douglas, and C. T. Amelink, "Quantitative, qualitative, and mixed research methods in engineering education," J. Eng. Educ., vol. 98, no. 1, pp. 53-66, Jan. 2009, doi: 10.1002/j.2168-9830.2009.tb01005.x. 
[22] J. M. Case and G. Light, "Emerging Research Methodologies in Engineering Education Research,” J. Eng. Educ., vol. 100, no. 1, pp. 186-210, 2011, doi: 10.1002/j.21689830.2011.tb00008.x.

[23] A. E. Jeffers, P. A. Beata, and B. Strassmann, "Qualitative assessment of the learning outcomes of an international service learning project in civil engineering," Int. J. Serv. Learn. Eng. Humanit. Eng. Soc. Entrep., vol. 10, no. 1, pp. 38-58, 2015, doi: 10.24908/ijsle.v10i1.5707.

[24] "Socially Engaged Design Academy," Center for Socially Engaged Design. https://umich.catalog.instructure.com/browse/csed/ (accessed May 01, 2020).

[25] M. R. Young, S. R. Daly, S. L. Hoffman, K. H. Sienko, and M. A. Gilleran, “Assessment of a novel learning block model for engineering design skill development: A case example for engineering design interviewing," 2017.

[26] J. A. Maxwell, Qualitative Research Methodology: An Interactive Approach, 3rd ed. Thousand Oaks, CA: SAGE Publications, 2013.

[27] J. W. Creswell and V. L. Plano Clark, Designing and Conducting Mixed-Methods Research, 3rd ed. Los Angeles, CA: SAGE Publications, 2018.

[28] M. Q. Patton, Qualitative Research \& Evaluation Methods, 4th ed. Thousand Oaks, CA: SAGE Publications, 2015.

[29] M. B. Miles, A. M. Huberman, and J. Saldana, Qualitative Data Analysis: A Methods Sourcebook, 3rd ed. Los Angeles, CA: SAGE Publications, 2014.

[30] J. L. Campbell, C. Quincy, J. Osserman, and O. K. Pedersen, "Coding In-depth Semistructured Interviews: Problems of Unitization and Intercoder Reliability and Agreement," Sociol. Methods Res., vol. 42, no. 3, pp. 294-320, Aug. 2013, doi: $10.1177 / 0049124113500475$.

[31] C. J. Atman, D. Kilgore, and A. McKenna, "Characterizing Design Learning: A MixedMethods Study of Engineering Designers' Use of Language," J. Eng. Educ., vol. 97, no. 3, pp. 309-326, 2008, doi: 10.1002/j.2168-9830.2008.tb00981.x.

[32] E. F. Redish and K. A. Smith, "Looking Beyond Content: Skill Development for Engineers," J. Eng. Educ., vol. 97, no. 3, pp. 295-307, 2008, doi: 10.1002/j.21689830.2008.tb00980.x.

[33] L. W. Anderson and D. R. Krathwohl, Eds., A Taxonomy for Learning, Teaching, and Assessing: A Revision of Bloom's Taxonomy of Educational Objectives. New York, NY: Longman, 2001.

[34] D. A. Kolb, Experiential Learning: Experience as the Source of Learning and Development. Englewood Cliffs, NJ: Prentice-Hall, 1984. 


\section{Appendix A - An example of how to apply "Why-How Laddering" to needs statements}

The following Why-How Laddering diagram was developed by Tallie Ritter, Jessica Kahn, Tanner Jones, and Christian Casanova as part of a recent student design project affiliated with the University of Michigan's Center for Socially Engaged Design and is shared with the design team's consent. This approach to comparing needs statements is based on an adapted version of the Why-How Laddering tool described in the Stanford d.school design thinking bootleg [7] and demonstrates how this tool may help engineering students balance breadth and specificity when developing needs statements for their design projects.

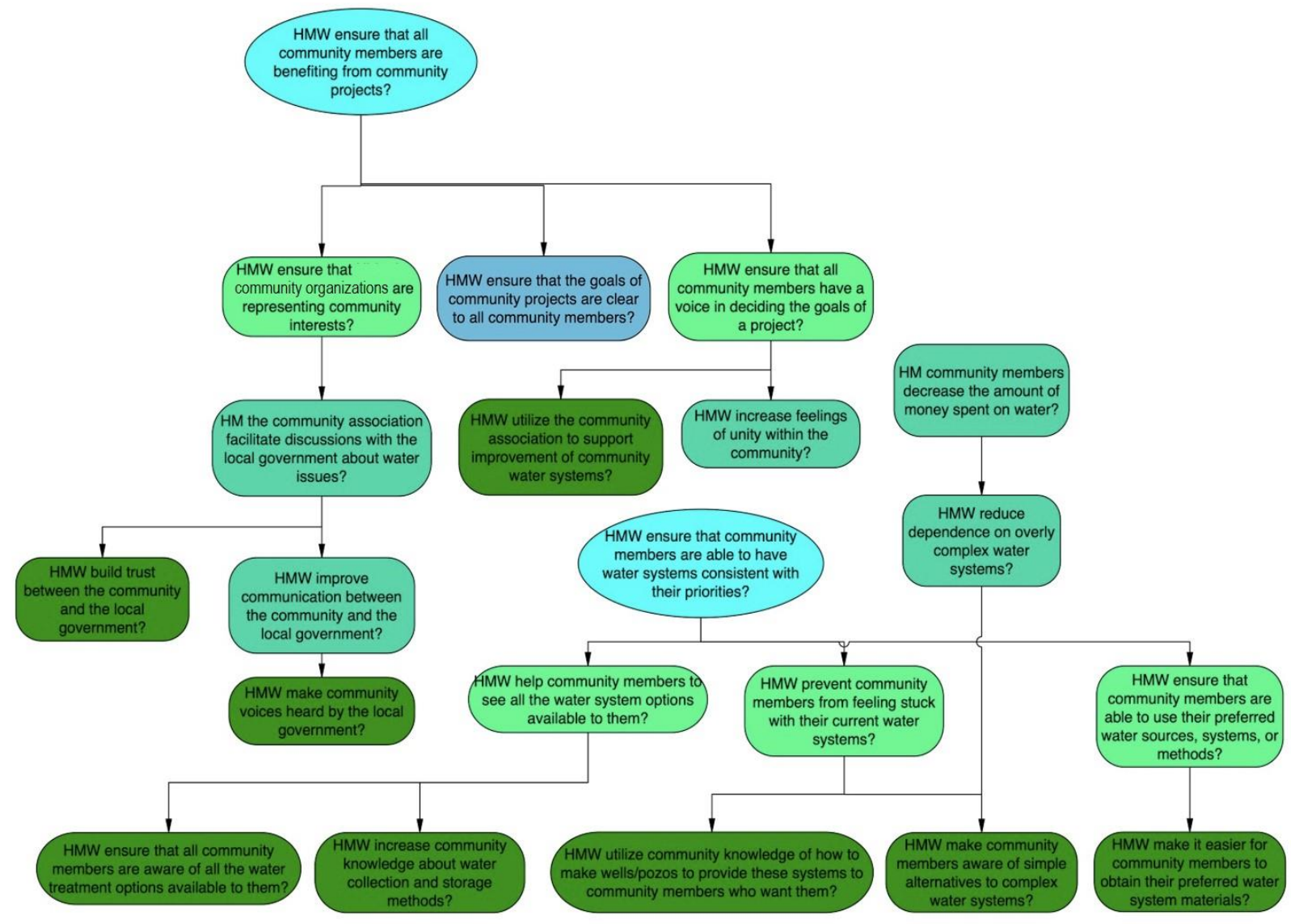

